\title{
A novel Adaptive Learning Management System Using Ontology
}

\author{
Shaimaa M.Nafea \\ School Of Business (Management Information System) \\ Arab Academy For Science Technology \& Maritime \\ Cairo,Egypt \\ shaimaa.nafea@aast.edu
}

Francois Siewe

School Of Computer Science and Informatics

De Montfort University

Leicester, UK

FSiewe@dmu.ac.uk

\author{
Leandros A. Maglaras \\ School of Computer Science and Informatics \\ De Montfort University \\ Leicester, UK \\ leandros.maglaras@dmu.ac.uk
}

\author{
M.Elemam Shehab \\ School Of Computer Science and Information System \\ Arab Academy For Science Technology \& Maritime \\ Cairo,Egypt \\ melemam9@gmail.com
}

\begin{abstract}
The success of web technologies has prompted a developing consideration on e-learning activities. Notwithstanding, most current e-Learning systems give static web-based learning with the goal that learners get to the same learning contents through the web, regardless of individual learners profiles. These learners may have altogether different learning foundations, information levels, learning styles, and capacities. The 'one size fit all' in an e-Learning frameworks is unmistakably a commonplace issue. To defeat this impediment and build powerful learning, versatile and customized learning is as of now a dynamic examination range. This paper propose a novel approach for designing and implementing adaptive learning management system based on ontology and semantic web technologies by offering a tailored model which represents the different activities that should be completed by learner. It offers a framework that is based on both learning styles and ontology to address the impact of student behavior.
\end{abstract}

Keywords_Personalised;E-Learning;Ontology;Personalised learning.

\section{INTRODUCTION}

The importance of personalization towards learner's requirements has until lately been concurred by all electronic direction researchers [1]. In any case, most current e-learning frameworks are taking into account one size fits all way to deal with substance conveyance. This issue of conveying the same substance to all learners can be tended to by adjusting learning substance to individual client's prerequisites [2]. Versatile learning is a discriminating prerequisite for $\mathrm{e}$ learning frameworks which progressively adjusts learning substance to learner's instructive requirements for advancing learning results [3]. In any case, such administrations are not regularly actualized legitimately by and large of e-learning as they oblige ceaseless adjusting of the diverse elements that ought to be utilized and how to utilize them. Late advancements of semantic web advances have demonstrated a pattern of utilizing ontologies to advance versatile e-learning which permits making particular client profiles and substance models. Ontologies are the most suitable means for speaking to information because of their adaptability and extensibility in planning ideas and their connections [4]. In existing elearning frameworks, same learning substance is conveyed to distinctive learners. Be that as it may, an advanced situation for one learner is not so much improved for another.

Inclinations, capacity and instructive levels of learners are shifted and different sorts of substance on learning points are needed to adjust the learning substance to the prerequisites of distinctive learners. The multifaceted nature of existing e-learning frameworks is in selecting learning substance and arrangements fitting to specific learners. Presently, there is no framework that recommends to learners the proper learning substance, exercises and arrangements taking into account learner's attributes and examination of past learning activities.

This paper proposes an ontological way to deal with creating customized e-learning framework. Our methodology proposes an ontological construction modeling including an autonomous versatile motor. This motor does exclude any learning around a specific space or any adjustment technique; it gets all the fundamental data from related ontologies. Both the motor and the adjustment procedure are kept separate and are along these lines reusable freely of one another. This partition together with the segments' discreteness of adaptively permits course creators to redesign and enhance the versatile e-learning framework iteratively without the need to change the current usage. 


\section{E-LEARNING}

Learning is characterized as an adjustment in human association or capacity that proceeds over a stretch of time and it is not just referable to procedures of development [5]. It is additionally used to allude to picking up learning and to mastering what is as of now thought about something; the development and elucidation of a man's own particular experience; or a requested, proposed procedure of testing thoughts identified with issues [6]. Learning procedure is thought to be improved when the learners are told about the pertinence of their learning and when they are offered time to consider the circumstance and have proficient input on their execution.

One of the instructive strategies is versatile learning in which showing and learning intentions are utilized, and the instructive assets are coordinated with the learners as per their own particular needs [6]. In their meaning of e-learning, Shoniregun and Dark [7] separate the term e-learning into two stages, the first of which depicts the conveyance framework as an electronic medium of conveying learning materials and the second of which handles the quality's manageability guidelines of the learning materials, denied of any thought of area. Fallon \& Brown [8] characterize E-learning as "any learning, preparing, or instruction that is encouraged by the utilization of surely understood and demonstrated PC innovations, particularly systems taking into account web innovation, including an immense arrangement of uses and procedures". E-learning contain a more extensive area than just web realizing, which includes utilization of all accessible electronic media to convey training and preparing in a more compelling way.

The expression "e-learning" is being utilized as a part of the system that embraces the universally useful of supporting an extensive variety of electronic media (Web, intranets, extranets, satellite show, sound/feature tape, intelligent television and Compact disc ROM) to make professional adapting more adaptable [9]. It is showing and learning through the web or whatever other advanced media, it makes full utilization of the learning environment with its enormous measure of assets and totally new correspondence system that is improved by cutting edge data innovation, to accomplish another pattern of learning [10]. In the long run, the entire picture of showing and instruction is considered to change. The established instructors' parts and in addition the relationship in the middle of educators and understudies in customary learning procedure are relied upon to change definitely. E-learning is a sort of discovering what is upgraded, supported or weighed by the utilization of advanced media. E-learning may incorporate the utilization of new or understood innovation and/or the development of new learning material. It might be made both by regional standards and at a separation [11].

\section{LEARNING STYLE}

Learning style is one of the individual contrasts that assume a vital part in learning. It is accepted to assign everything that is trademark to a person when she/he is learning, i.e. a particular way of drawing nearer a learning assignment, the learning methods enacted keeping in mind the end goal to satisfy the undertaking, and so forth [12]. A few definitions were utilized to allude to learning style. It is characterized as "and inclination with respect to a few understudies to embrace a specific learning system paying little mind to the particular requests of the learning assignment" [13].

Another definition proposes it as "the composite of trademark intellectual, viable, and mental components that serve as generally stable pointers of how a learner sees, cooperates with, and reacts to the learning environment" [14]. A further definition is "an individual's favored way to deal with sorting out and showing data" [15]. Based on the current literature, learning style has been credited a few models, as indicated in the following table.

TABLE 1 :LEARNING STYLE[15].

\begin{tabular}{|l|l|}
\hline \multicolumn{2}{|c|}{ Learning style } \\
\hline 1 & Index of Learning Styles of Felder and Silverman (1988); \\
\hline 2 & Learning Styles Theory of Kolb (1985); \\
\hline 3 & Learning Styles of Honey and Mumford (1992); \\
\hline 4 & Student Learning Style Scales of Grasha (1996); \\
\hline 5 & Multiple Intelligences of Gardner (1999); \\
\hline 6 & Auditory Visual Tactile Learning Styles of Sarasin (1998). \\
\hline
\end{tabular}

Why Felder-Silverman Learning Style Model

FSLSM is the most suitable educational and noise model where it combines many learning style categories FSLSM is the most suited for the students' environment as it also considers the psychological aspects of a person . The index of learning styles is a questionnaire based approach is that it suffers from the "inaccurate self-conceptions of students" .to be more accurate it not only depends on questionnaires but also tacking student's behavior during their studying.

\section{Felder-Silverman Learning Styles}

As per Felder that every individual distinction that incorporate individual inclinations for learning, instructive exercises, furthermore educated and mental contrasts are alluding to the learning style of a person. The learning style of a learner ought to be considered as far as presentation, association, preparing and digestion of data [16]. He proposes a model made out of four measurements with the presumption that the understudy's learning style may be characterized to some degree by the responses to four inquiries [17]: 
1. How does the student want to process data: "effectively" through engagement in physical action or exchange, or "cogitatively" through self-contemplation?

2. What sort of data does the student specially see: "tactile" sights, sounds, physical sensations, or "natural" recollections, thoughts, experiences?

3. Through which methodology is tactile data most successfully seen: "visual" pictures, charts, diagrams, exhibits, or "verbal" sounds, composed and talked words and recipes?

4. How does the understudy progress toward seeing "consecutively" in a coherent movement of little incremental steps, or "all inclusive" in substantial bounced, comprehensively?

Felder proposes the ILS questionnaire (List of Learning Styles) that is made out of 44 shut inquiries with two choices as replies (an and b) by framing 4 gatherings of 11 inquiries to assess the position of a student on a scale [18]. Every gathering of inquiries characterizes a measurement of the intellectual model of a student that is made out of four measurements (D1, D2, D3 and D4). Each measurement ranges from - 11 to 11 with the accompanying degrees [16]:

- $\quad$ From 1 to 3: uncertain

- $\quad$ From 5 to 7: Moderate

- $\quad$ From 9 to 11: strong

(a)

\begin{tabular}{|c|c|c|c|}
\hline D1:Reflecttion & Active & & Reflective \\
\hline D2:Reassoning & -11 & 0 & $\begin{array}{c}11 \\
\text { Intuitive }\end{array}$ \\
\hline $\begin{array}{l}\text { DL:Keassoning } \\
\text { D3:sensory }\end{array}$ & $\begin{array}{l}-11 \\
\text { Visual }\end{array}$ & 0 & $\underset{\substack{11 \\
\text { verbal }}}{\longrightarrow}$ \\
\hline D4:Progression & $\begin{array}{l}-11 \\
\text { Sequential }\end{array}$ & 0 & $\underset{\text { Global }}{\overrightarrow{11}}$ \\
\hline & -11 & 0 & $\overrightarrow{11}$ \\
\hline
\end{tabular}

Fig. 1. The four dimensions of the ILS questionnaire of Felde[16]

A. The first measurement D1, is the reflection. It changes (ranges) from dynamic to intelligent. Dynamic learners have a tendency to hold and comprehend data best by doing something dynamic with it, talking about or applying it or disclosing it to others. Intelligent learners want to consider it unobtrusively first. They were likewise found to lean toward gathering work more than intelligent learners, who support individual work. Going to addresses without getting occupied with any physical work aside from taking is hard for both learning sorts, however especially hard for dynamic learners.

B. The second measurement D2, is the thinking. It differs from detecting to instinctive. Detecting learners are accepted to tend to learning realities, while instinctive learners are asserted to incline toward finding conceivable outcomes and connections. Likewise, sensors regularly like tackling issues by settled systems and aversion intricacies and amazements; intuitors like development and abhorrence redundancy. Sensors are more probable than intuitors to dislike being tried on material that has not been expressly secured in class. Sensors have a tendency to be understanding with points of interest and great at remembering actualities and doing hands-on (research facility) work; intuitors may be better at getting a handle on new ideas and are frequently more agreeable than sensors with reflections and scientific definitions. Sensors additionally have a tendency to be more functional and cautious than intuitors; intuitors tend to work speedier and to be more creative than sensors. Lastly, sensors don't care for courses that have no obvious association with this present reality; intuitors don't care for "attachment andchug" courses that include a ton of retention and routine computations.

C. The third measurement $D 3$, the tactile, differs from visual to verbal. Visual learners recollect best what they see, similar to pictures, outlines, stream graphs, courses of events, movies, and showings. Verbal learners get more out of words, composed and talked clarifications. Everybody adapts more when data is introduced both outwardly and verbally.

D. The last measurement D4, the movement, differs from successive to worldwide. Successive learners tend to increase understanding in straight strides, with every progression taking after consistently from the past one. Worldwide learners have a tendency to learn in expansive hops, engrossing material arbitrarily without seeing associations, and after that all of a sudden "getting it". Likewise, successive learners have a tendency to take after intelligent stepwise ways in discovering arrangements; worldwide learners may have the capacity to tackle complex issues rapidly or set up things together in novel ways once they have gotten a handle on the master plan, yet they may experience issues clarifying how they did it [19]. 


\section{SEMANTIC WEB MINING AND ONTOLOGY}

\section{A. Semantic Web}

The Semantic Web is considered as the up and coming era of the web advances where data is given "a very much characterized importance", better empowering PCs and individuals to work in collaboration [20]. Semantics empower PCs to process, change and collect data to settle on more astute choices. A few innovations have been produced for forming, building and adding to the semantic web. Such advances bolster fine grained semantic structures for web assets [21].

Nowadays, these advancements are being connected in numerous handy applications to semantically show the learning in their individual areas. In the field of customized elearning, ontologies are connected to model information about learning substance, learner's profile and instructing procedures. Figure 2 demonstrates the semantic web stack, which shows the chain of command of the included advances [22]. The advancements from the stack's base up to Metaphysics Web Dialect (OWL) are until now institutionalized.

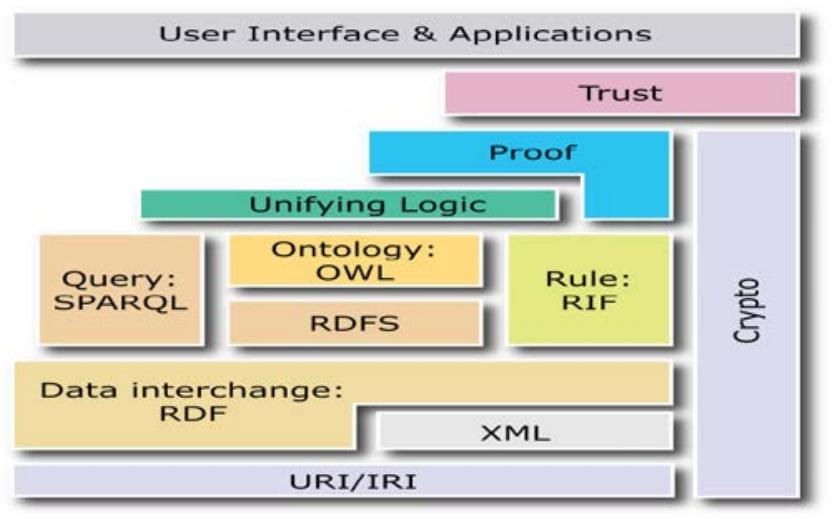

Fig. 2. Semantic Web Stack [22]

\section{B. Ontology}

Ontology is a branch of rationality where it alludes to the hypothesis of presence [23]. The investigation of cosmology does a reversal to the works of Plato and Aristotle which comprises of progressively ordering various types of element and their elements [24]. Cosmology has been generally utilized as a part of late years in the field of counterfeit consciousness and software engineering, particularly in areas such as, savvy data incorporation [25], agreeable data frameworks [26], learning representation [27], data recovery and extraction [28] and database administration frameworks [29][30].

Accessible writing on ontological designing focuses to various definitions for portraying what cosmology is. A standout amongst the most generally utilized meanings of cosmology is by Gruber [31] where Metaphysics is characterized as a formal, express detail of a conceptualization. Conceptualization underlines that philosophy speaks to a dynamic model of a marvel on the planet as it serves to recognize suitable space ideas and semantic connections among these ideas with formal definitions as far as aphorisms [32]. Such sayings are revelatory which empowers metaphysics to speak to the conceptualization definitively.

Unequivocally in the ontology definition expresses that the kind of ideas and the requirements on their utilization are characterized expressly. Convention implies that the cosmology forestalls unforeseen elucidation of the idea, relations and requirements. Accordingly, it empowers cosmology to be machine-coherent. Studer [33] characterizes cosmology as a formal, express detail of a mutual conceptualization. Shared implies that philosophy catches concurred information; it is not private for some individual and acknowledged by a gathering [33].

Learning representation utilizing ontologies encourages arranging the metadata of complex data assets. These metadata give syntactic and semantic data about data assets which are encoded as occurrences in the ontology [34].

\section{ONTOLOGY AND E-LEARNING}

Few papers discuss about the expansion of both ontology and learning style models. For such novel system, we will likewise research the parts' reusability of adaptively and the adaptability and extensibility of the frameworks that actualize this methodology and also outline and create three space ontologies (course content, understudy model and test model).

In [35], cosmology to depict learning items is proposed, utilizing a few components of the IEEE LOM standard. Four measurements of the Felder and Silverman model are spoken to as Learning Style Characteristics. In [36], a domain is proposed to prescribe clients showed as accomplices in a communitarian learning environment. To speak to learning styles, the LOCO (Learning Item Setting Cosmology) metaphysics is utilized to speak to learning styles, which has the Learning Style and the Learning Style Classification as its fundamental classes. The Learning Style class speaks to the learning style of a man and the Learning Style Classification classifies the measurements of the Felder and Silverman model. The Learning Style Model permits the representation of classifications and learning styles of distinctive models. Gasparini [37] proposes cosmology to speak to inclining materials, collecting information level, perusing level and learning style, to be utilized as a part of the learning environment Adjust Web. The Learning Material and Learning Style classes are proposed, and additionally the Visual and Verbal subclasses of the Learning Style class. The target of metaphysics is to encourage the proposal of materials more satisfactory to the learner's profile. Just the 
Visual/Verbal measurements of the Felder and Silverman model are considered.

Huang and Duan [38] propose a redid semantic learning environment. Through surmising components, the objects' attributes are contrasted and the learner's customized parameters and substance are suggested for them. With respect to learning styles, the fundamental philosophy classes proposed are Learner and Learning Style. Every measurement of the Felder and Silverman model are spoken to as characteristics of the Learning Style class. Along these lines the learning styles spoke to are confined to the Felder and Silverman model.

Customized administrations are nowadays an imperative exploration issue in the field of e-learning in light of the fact that no altered learning ways will be proper for all learners. It is regularly trusted that each individual learns as indicated by their own particular learning background, style, needs and premium. Hence, personalisation and intuitiveness will advance the nature of learning for individual learners. In this way, in an e-learning framework, the capacity to distinguish and adjust learner's necessities gives an intense personalisation system.

To realize personalised e-learning framework, all users have components in user models. User models comprise of an arrangement of data which depicts user qualities, for example, inclinations and foundation learning [39]. The framework creates a superior using so as to learn undertaking the data in the client model. Besides, amid the learning procedure client model will be always upgraded in view of the client's cooperation with the learning environment.

Baylari et al has displayed a customized multispecialists e-Learning framework which exhibits versatile tests and goes about as a human educator and gives the learners a benevolent and customized showing environment [40]. Late advancements of semantic web innovations have demonstrated a pattern of utilizing metaphysics to advance versatile learning administrations which permits us to make particular client profiles that can help amid the learning procedure.

Vassileva et al [41] outline a stage which comprise of writing device, educator instrument and adjustment motor controlling the substance conveyance versatile to individual learners. For this reason, framework performing artists ought to take after particular work processes of versatile courseware outline and conveyance. In this framework creators need to plan learning philosophy diagrams arranging mixed media learning articles (LOs), and metadata for both the metaphysics and LOs. The work processes of exercises incorporate substance creators, course educators, chiefs of the motor controlling adjustment prepared and, at long last, the learners. Gemmis et al [42] proposed an augmentation of the vector space recovery model in which client profiles learned by substance based recommender framework. Skillet et al built up a semantic based quest technique for customized e-learning. They outlined learner metaphysics and learning asset cosmology for semantic examination and calculation for philosophy semantic [42]. A customized e-learning framework must have the capacity to tailor the instructive experience to a specific learner. To accomplish this objective, a semanticbased versatile motor is proposed to examinations learners' reactions and conduct to standard exercises and tests. Amid the following level of taking in, the framework proposes suitable learning ways in view of examinations information in versatile motor. The customized e-learning system was proposed in [43]. The e-learning technique depends on mixture sifting. Two-level client profiles coordinate the suggestion process. Gathering profile mirrors the clients whose comparable adapting needs are comparable with the present client. Point profile portrays the client's advantage with subjects that the client has learned. Gathering profile and theme profile are bases of cooperative sifting proposal and substance based separating suggestion separately.

S. Cakula and M. Sedleniece personalized elearining using ontology for modelling learning tree inside learning management system [44].

Sarma Cakula has displayed Ontologies' in learning management system from different perspective : firstly using common vocabulary for multi-agent system, secondly as a chain between heterogeneous educational systems, ontologies for pedagogical resources sharing or for sharing data and ontologies used to mediate the search of the learning materials on the Internet [45].

\section{PROPOSED MODEL}

The following section illustrates the proposed adaptive e-learning system which is based on ontologies. It also demonstrates the individual components needed to implement the novel approach (See Figure 3). The structure of the proposed model consists of six major components namely: Student interface, Course model, course manager, student model, test model and adaptation engine.

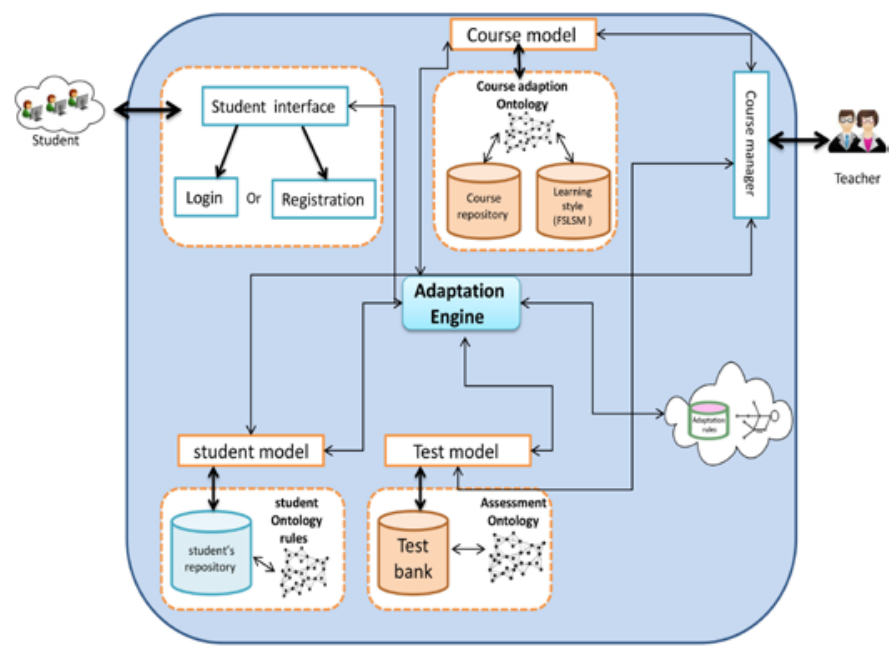

Fig. 3. The structure of proposed model 
In the following paragraphs, we will show the functionalities of each component of proposed adaption model are described:

1. Student Interface: Student Interface is the communication component that controls the interaction between student and the system. It deals with the account of learner's such as (registration and login) and facilitates the learner's interaction with the learning components. It also captures the learner's responses in interactive activities and transfers them to the Adaptive Engine. This information is used in order to choose the correct course material from the course adaptation ontology machine.

2. Student Model : Student model holds information about the students. Such information comprises categories of Knowledge, preferences and behavior like No. of visits, No. of visits and time spent on exercises Amount of time dealt with reading material etc. The system uses this information in order to adapt to learner's individual needs. The system step by step updates the learner model during the learning process, in order to keep track of learner's actions and progress and possibly guide the learner accordingly. Student model is responsible for retrieving the characteristics of a particular learner, making the necessary changes and sending it to the adaptation model through interaction with the repository. The system also receives the knowledge about new learners from the User Interface and stores it in the student model. student model is updated when it receives new information about the learner from the adaptive engine. This data is utilized as a part of request to build an ontological model taking into account their own particular inclinations.

3. Course Model: Content Model stores all essential learning content and also describes how the information content is designed. It is responsible for finding the learning objects stored in the repository, which meet some given criteria This information is used as a piece of coordinating the most suitable course substance arrangement in light of ontology adaption machinsm .

4. Test model : contains all crucial tests specifications to accurately evaluate the learner's level of knowledge. It also searches the test bank to find appropriate assessments required by the adaptation model.This data is utilized as a part of request to suggest test in diverse level taking into account understudy level from test adjustment ontology machine.

5. Course Manager : handles requests from the authors and instructional designers for inserting, updating and modifying the structure of course, instances of IOs and adaptation rules. It also allows the test developer to add new assessments and update them through the assessment model.
6. Adaptation Engine ( $A E)$ : is at the core of the system design and is contain rules to support the adaptive functionality of the system. Different conditions are modeled in the body of the rules. These conditions are all obtained from different models such as student, Content and test models as well as generating and recommending adaptive learning paths according to learner's behavior and their progress to recommend the most suitable adaptive content to meet their learning style.

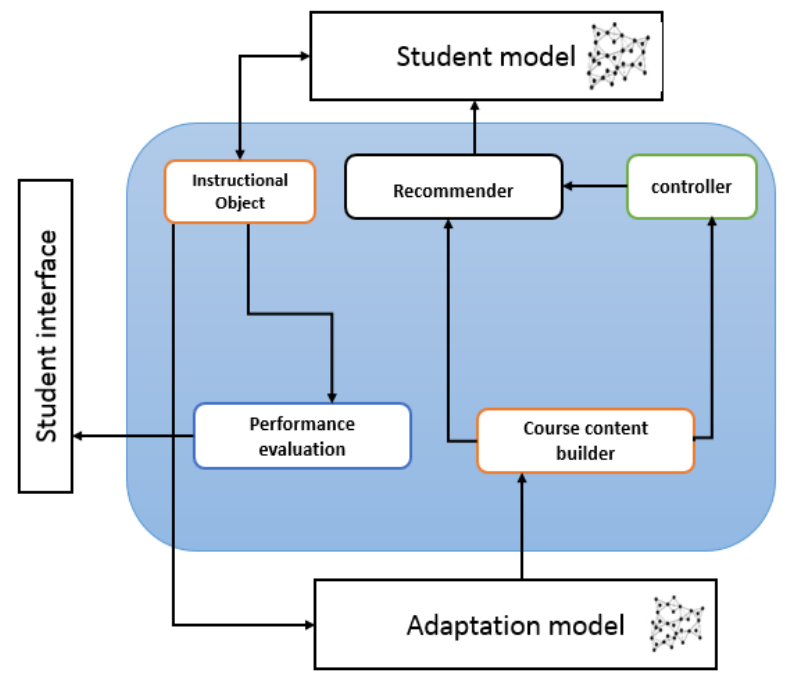

Fig. 4. The Adaptation engine

Figure 4 shows the internal architecture of The Adaptation engine. The engine consists of the following main parts:

1. Course content builder (CCB): CCB makes adaptive decisions about learner's knowledge from adaptation model and about the structure of the course from domain model, to construct the proposed annotated course structures. Adaptation model gets student's level of knowledge from student model and prerequisite relation between different topics from domain model to make related decisions.

2. Controller: suggests the adaptation model which is based on the difficulty level of the interactive IOs, the result of analyzing learner's response to them, difficulty level of content and defined activities in instructional design. For example, if a learner is given a learning content with moderate or high difficulty level and he/she fails even to answer the related easy exercises, the recommender suggests him/her to repeat learning this topic with a lower difficulty level.

3. Recommender: suitable IOs to provide adaptive learning content dynamically. It knows how to combine the suggested IOs to form a coherent learning content that best suits a particular learner. In more detail, adaptation model selects the IOs which are suitable for the learner. 
Recommender gets these and also the instructional design from the content model. It deletes the IOs which are presented to the learner in previous learning steps to prevent presenting them again, and then organizes the remaining IOs according to activities defined in instructional design. Finally, the generated personalised content is delivered to the learner through the User Interface.

4. Instructional object: receives the learner's responses to interactive IOs in order to then analyse them and provide suitable feedback to learner. This unit updates the learner model based on the information earned during the analysis of learner's responses.

5. Performance evaluation: receives the learner's responses to the presented assessments and analyses them. Then, according to the result of this analysis, the appropriate feedback is provided to the learner and the learner model is updated accordingly. As well as receives the learner's responses to tests from the assessment unit.Also learner model is updated according to this new ability.

\section{USED TOOL}

Protégé was developed by the Knowledge Modeling Group at Stanford Medical Informatics. Protégé is an ontology editor that is designed for the creation of large knowledge bases [46]. Protégé-Frames is used for constructing framebased domain ontologies, and Protégé-OWL is used for constructing OWLcompliant ontologies. The ontologies created by Protégé, which is implemented in Java, can be exported to a different format such as RDF, OWL, and XML schema. Other applications can access the knowledge base using the getKnowledgeBase() API. Protégé is available as an open source application and has a strong user community, the academic and government users in that community develop diverse applications ranging from modeling and simulation to geospatial tools.

\section{VIII.EXPERIMENTAL EVALUATION}

The proposed ontoglical adaptive model will be evaluated from two aspects:

1. Learner's satisfaction: Examining whether the generated adaptive learning paths are pedagogically effective and satisfactory for learners and teachers.

2. Flexibility, extensibility and reusability: Examining the flexibility, extensibility and reusability of proposed which is the result of using ontology .
At the end of the experiment, each learner will be presented with a questionnaire to fill in so we can collect learners' opinions on the adaptive learning regarding the following categories namely: Learner's opinion about adaptive and non-adaptive system; Satisfaction with adaptive navigation; Appropriateness of the personalised content; Usage of the adaptive guidance and finally Learner's interests.

Teachers are responsible for controlling e-learning courses and integrating them as a part of the instructional curriculum they are responsible for . For instance student progress while using adaptive system .

In the evaluation process, 150 students from arab academy for science and technology and maritime transport will be selected to work with the system to learn several topics after that In students will take two exams, one before and one after working with the system, namely the pre and post-tests. At the end of the experiment, each learner will fill-out a questionnaire to reflect his/her perceptions about different aspects of the system.

In the evaluation process, 150 students from arab academy for science and technology and maritime transport will be select to work with the system to learn several topics after that In students will take two exams, one before and one after working with the system, namely the pre and post-tests.

At the end of the experiment, each learner will fillout a questionnaire to reflect his/her perceptions about different aspects of the system. This way we will be able to measure the pedagogical effectiveness of the system and student satisfaction of the proposed adaptive learning mechanism.

\section{CONCLUSIONS}

The 'one size fit all' in an e-Learning frameworks is unmistakably a commonplace issue. To defeat this impediment and build powerful learning, versatile and customized learning is as of now a dynamic examination range. In order to cover the need for adaptive learning methods, this paper presents a semantic rule-based approach which is based on separated ontological domain in order to offer a personalised learning content. Eenriching ontologies with semantic rules increases the reasoning power and helps to represent adaptation decisions.

This novel approach aims to improve flexibility, extensibility and reusability of learning systems, while offering pedagogically effective and satisfactory learning experiences for learners. Moreover, semantic rules facilitate runtime incorporation of discrete adaptivity components to generate flexible personalisation during the learning process. 


\section{REFERENCES}

[1] H. D. Surjono, "The Design of Adaptive E-Learning System based on Student's Learning Styles," International Journal of Computer Science and Information Technologies, vol. 5, pp. 2350-2353, 2011.

[2] V. Esichaikul, S. Lamnoi, and C. Bechter, "Student Modelling in Adaptive E-Learning Systems," Knowledge Management \& E-Learning: An International Journal, vol. 3, pp. 342-355, 2011.

[3] H.-Y. Jeong, C.-R. Choi, and Y.-J. Song, "Personalized Learning Course Planner with E-learning DSS using user profile," Expert Systems with Applications, vol. 39, pp. 2567-2577, 2012.

[4] P. Mohan and C. Brooks, "Learning objects on the semantic Web," in Advanced Learning Technologies, 2003. Proceedings. The $3^{\text {rd }}$ IEEE International Conference on, 2003, pp. 195-199.

[5] Brown, Roswyn A., and Barbara Hawksley. Learning Skills, Studying Styles and Profiling. Quay Books, 1996.

[6] Smith, Robert McCaughan. Learning How To Learn. Milton Keynes: Open University Press, 1983.

[7] Shoniregun, C., \& Gray, S. (2003). Is E-Learning Really The Future Or A Risk? Ubiquity, 4(10), 1-1.

[8] Fallon, C., \& Brown, S. (2003). e-learning standards: a guide to purchasing, developing, and deploying standards conformant e-learning. London, New York, Washington, D.C., Boca Raton: St.Lucie Press.

[9] Smith, Peter J. "Workplace learning and flexible delivery." Review of Educational Research 73.1 (2003): 53-88.

[10] Gagné, Robert M, The Conditions Of Learning And Theory Of Instruction. New York: Holt, Rinehart and Winston, 1985.

[11] Khan, Badrul Huda, ed. Managing e-learning: Design, delivery, implementation, and evaluation. IGI Global, 2005.

[12] Popescu Elvira (2008). Thesis: "Dynamic adaptive hypermedia systems for e-learning". November 2008.

[13] J.J. Beshuizen and E.T. Stoutjesdijk (1999). "Study Strategies in a Computer Assisted Study Environment". Learning and Instruction, 9, pp. 281-301.

[14] J. Keefe (1979). "Learning Style: An Overview". NASSP's Student Learning Styles: Diagnosing and Prescribing Programs, pp. 1-17.

[15] R. J. Riding and S. Rayner (1998). "Cognitive Styles and Learning Strategies: Understanding Style Differences in Learning and Behaviour". David Fulton Publishers.

[16] Piombo Christophe (2007). Thesis: "Modélisation probabiliste du style d'apprentissage et application à l'adaptation de contenus pédagogiques indexés par une ontologie". October 2007.

[17] Felder Richard (1993). "Reaching the Second Tier: Learning and Teaching Styles in College Science Education". J. College Science Teaching, 23(5), 286-290. 1993.

[18] Felder Richard and Silverman Linda (1988). "Learning and Teaching Styles in Engineering Education". Engr. Education, 78(7), 674-681. 1988.

[19] Felder Richard and Soloman Barbara (2001). "Learning Styles and Strategies". Online at: http://www4.ncsu.edu/unity/lockers/users/f/felder/public/ILSdir/ styles.htm

[20] Berners-Lee, T., Hendler, J. \& Lassila, O. (2001), 'The semantic web’, Scientific American 284(5),pp. 34-43.

[21] Dolog, P. (2006), Knowledge Representation and Reasoning in Personalized Web-Based e-Learning Applications, VSB-Technical University of Ostrava.

[22] Brewster, C. \& O’Hara, K. (2007), 'Knowledge representation with ontologies: Present challengesfuture possibilities', International Journal of Human-Computer Studies 65(7),pp. 563 - 568.

[23] Smith, B. (2003), ontology, in L. Floridi, ed., 'The Blackwell Guide to the Philosophy of Computing and Information', Oxford: Blackwell, pp. 155-166.

[24] Horrocks, I. (2008), 'Ontologies and the semantic web', Communications of the ACM 51(12),pp. 58-67.
[25] Seng, J.-L. \& Kong, I. (2009), 'A schema and ontology-aided intelligent information integration', Expert Systems with Applications 36(7),pp. 10538 - 10550.

[26] Ouksel, A. M. \& Sheth, A. (1999), 'Semantic interoperability in global information systems', SIGMOD Rec. 28(1),pp. 5-12.

[27] Brewster, C. \& O’Hara, K. (2007), ‘Knowledge representation with ontologies: Present challengesfuture possibilities', International Journal of Human-Computer Studies 65(7),pp. 563 - 568.

[28] M“uller, H.-M., Kenny, E. E. \& Sternberg, P. W. (2004), 'Textpresso: An ontologybased information retrieval and extraction system for biological literature', PLoS Biol 2(11),pp. e309.

[29] Necib, C. \& Freytag, J.-C. (2003), Ontology based query processing in database management systems, in R. Meersman, Z. Tari \& D. Schmidt, eds, 'On The Move to Meaningful Internet Systems 2003: CoopIS, DOA, and ODBASE', Vol. 2888 of Lecture Notes in Computer Science, Springer Berlin Heidelberg, pp. 839-857.

[30] final specification'. Snae, C. \& Br"ueckner, M. (2007), 'Ontologydriven e-learning system based on roles and activities for thai learning environment', Interdisciplinary Journal of E-Learning and Learning Objects 3,pp. 1-17.

[31] Gruber, T. R. (1993), 'A translation approach to portable ontology specification', Knowledge Acquisition 5(2),pp. 199-220.

[32] Chi, Y.-L. (2009), 'Ontology-based curriculum content sequencing system with semantic rules', Expert Systems with Applications 36(4),pp. 7838 - 7847.

[33] Studer, R., Benjamins, V. R. \& Fensel, D. (1998), 'Knowledge engineering: Principles and methods', Data Knowl. Eng. 25(1-2),pp. 161-197.

[34] Dolog, P. \& Nejdl, W. (2007), The adaptive web, Springer-Verlag, Berlin, Heidelberg, chapter Semantic web technologies for the adaptive web, pp. 697-719.

[35] J. M. Gascuena, A. Fernandez-Caballero, and P. Gonzalez, "Domain Ontology for Personalized E-Learning in Educational Systems”, Sixth IEEE International Conference on Advanced Learning Technologies (ICALT'06), pp. 456-458, 2006.

[36] M. Siadaty, D. Gasevic, and M. Hatala, "Let's Meet: Integrating Social and Learning Worlds”, 2009 International Conference on Computational Science and Engineering, pp. 879-884, 2009.

[37] I. Gasparini, D. Lichtnow, and M. S. Pimenta, J. P. Oliveira, "Quality Ontology for Recommendation in an Adaptive Educational System”, International Conference on Intelligent Networking and Collaborative Systems, pp. 329-334, 2009.

[38] C. Huang, Y. Ji, R. Duan, “A semantic web-based personalized learning service supported by on-line course resources”, Networked Computing (INC), 6th International Conference, pp. 1-7, 2010.

[39] E. Alfonseca, P. Rodríguez, and D. Pérez, "An approach for automatic generation of adaptive hypermedia in education with multilingual knowledge discovery techniques," Computers \& Education, vol. 49, pp. 495- 513, 2007.

[40] A. Baylari and G. A. Montazer, "Design a personalized elearning system based on item response theory and artificial neural network approach," Expert Systems with Applications, vol. 36, pp. 8013-8021, 2009.

[41] D. Vassileva and B. Bontchev, "Activities workflow of adaptive courseware design and delivery," in IADIS International Conference MCCSIS 2009, Algarve, Portugal, 2009, pp. 223 - 230.

[42] M. d. Gemmis, et al., "A retrieval model for personalized searching relying on content-based user profiles," presented at the Association for the Advancement of Artificial Intelligence, 2008.

[43] J. Pan, et al., "A personalized semantic search method for intelligent elearning," presented at the International Conference on Intelligent Pervasive Computing, Washington, DC, USA 2007.

[44] S. Cakula and M. Sedleniece, "Development of a personalized elearning model using methods of ontology,” Procedia Computer Science, vol. 26, pp. 113-120, 2013.

[45] Sarma Cakula, Abdel-Badeeh M. Salem, "E-Learning Developing Using Ontological Engineering”, WSEAS transactions on Information Science and Applications, Issue 1, Volume 10, January 2013.

[46] Protégé, Available: http://protege.stanford.edu/ 